Nuntius Antiquus, Belo Horizonte, v. 13, n. 2, p. 241-262, 2017

\title{
Uma breve história das contradições: de Aristóteles à paraconsistência ${ }^{1}$
}

\section{A Brief History of Contradictions: From Aristotle to Paraconsistency}

\author{
Abílio Rodrigues Filho \\ Departamento de Filosofia \\ Universidade Federal de Minas Gerais, Belo Horizonte, Minas Gerais / Brasil \\ abilio.rodrigues@gmail.com
}

Resumo: O objetivo deste texto é apresentar um breve relato de como contradições e o princípio da explosão foram pensados no decorrer da história da filosofia, da formulação aristotélica do princípio da não contradição até a paraconsistência contemporânea, passando pela formulação do princípio da explosão na Idade Média e pela discussão sobre contradições na modernidade, especialmente em Hegel.

Palavras-chave: contradições; princípio da explosão; lógica paraconsistente; dialeteísmo.

Abstract: This paper is a brief presentation of how contradictions and the principle of explosion have been discussed in the history of philosophy. Starting with Aristotle's presentation on the principle of non-contradiction, we will see how these issues have been discussed in the Middle Ages, in the work of Kant and Hegel, and in the contemporary approaches to paraconsistency.

Keywords: contradictions; principle of explosion; paraconsistent logic; dialetheism.

${ }^{1}$ Este texto corresponde, com algumas modificações, à palestra ministrada no $V I I$ Simpósio Lendo, Vendo e Ouvindo o Passado: entre Aporias, Dilemas, Paradoxos e Labirintos, realizado em São João Del-Rei, em abril de 2017. 


\section{Introdução}

Uma contradição é um par de proposições tal que uma é a negação da outra, $A$ e $\sim A$, ou uma conjunção de tais proposições $A \wedge \sim A$. Os símbolos $\sim, \wedge, \vee \mathrm{e} \rightarrow$ serão usados aqui para representar, respectivamente, a negação $n a \tilde{o}$, a conjunção $e$, a disjunção ou e a condicional se... então. Contradições são em geral rejeitadas no discurso tanto das ciências quanto da vida cotidiana. Quando perguntamos exatamente por que contradições são rejeitadas, a resposta é imediata: porque proposições $A$ e $\sim A$ não podem ser ambas verdadeiras. Mas o fato de contradições serem em geral rejeitadas não significa que elas sejam sempre rejeitadas, nem que não ocorram em contextos argumentativos reais. Pelo contrário. Há diversos contextos argumentativos em que temos de lidar simultaneamente com pares de proposições contraditórias, que não podem ser simplesmente descartadas.

A discussão sobre contradições, de fato, é quase tão antiga quanto a filosofia. Em relação à Antiguidade Grega, Heráclito é considerado por alguns intérpretes, inclusive Aristóteles, um defensor da tese de que a realidade é contraditória. Mas veremos que é bastante duvidoso que as ideias de Heráclito de fato sejam violações do princípio da não contradição. Aristóteles, no livro $\Gamma$ da Metafísica, apresenta uma defesa do princípio da não contradição (daqui em diante $P N C$ ) que até hoje serve como parâmetro para a discussão sobre contradições. Ainda que os argumentos de Aristóteles tenham sido criticados na literatura (e.g. ŁUKASIEWICZ, 1979; PRIEST, 2005), a chamada formulação ontológica do princípio da não contradição expressa uma ideia amplamente aceita: nenhum objeto pode ter e não ter uma propriedade, ao mesmo tempo e sob o mesmo aspecto.

$\mathrm{O} P N C$, na verdade, não proíbe asserir contradições, mas apenas afirma que uma asserção de uma contradição será sempre falsa. $\mathrm{O}$ que é de fato eficaz em proibir contradições é o princípio da explosão (daqui em diante $E X P$ ), uma inferência válida na lógica clássica que permite concluir qualquer proposição da linguagem na presença de uma contradição, em símbolos, 


$$
A \wedge \sim A \vdash B,
$$

em que o símbolo $\vdash$ representa a relação de consequência lógica e é lido "... implica logicamente que...", ou na forma de um axioma,

$$
A \rightarrow(\sim A \rightarrow B),
$$

sendo $B$ qualquer proposição. Por exemplo, dadas as proposições abaixo:

Haverá uma reunião do departamento às $14 \mathrm{~h}$ do dia $16 \mathrm{de}$ novembro de 2017;

Não haverá uma reunião do departamento às 14 h do dia 16 de novembro de 2017;

o EXP permite concluir que $2+2=5$, que a Terra é plana, e até mesmo que o Brasil venceu a Copa de 2014. Essa circunstância em que todas as proposições da linguagem podem ser provadas é chamada trivialidade. Naturalmente, trivialidade é intolerável. Portanto, sendo válido o EXP, contradições têm necessariamente que ser evitadas. EXP é válido na lógica clássica, que é o tratamento padrão da consequência lógica que encontramos invariavelmente em livros de introdução à lógica. Por outro lado, é certo que diante de um par de informações contraditórias, como as proposições acima, ninguém vai tirar conclusões descabidas e irracionais - sim, irracionais, pois concluir qualquer coisa de uma contradição é irracional, ao passo que lidar de modo racional com o par de proposições acima é justamente não aplicar o princípio da explosão.

Tanto do ponto de vista técnico quanto do conceitual, $P N C$ e $E X P$ são independentes: um pode ser endossado sem que o outro o seja. Não vamos entrar em detalhes técnicos aqui, mas para mostrar que tais princípios são independentes, considere um sistema proposicional da lógica clássica com os axiomas usuais para os conectivos $\rightarrow, \wedge \mathrm{e} \vee$, mais os seguintes axiomas para a negação:

$$
\begin{array}{ll}
A \vee \sim A & \text { (terceiro excluído), } \\
A \rightarrow(\sim A \rightarrow B) & (E X P) .
\end{array}
$$

Se nesse sistema $E X P$ é substituído pela não contradição, 


$$
\sim(A \wedge \sim A) \quad(P N C),
$$

o sistema assim obtido não é equivalente ao primeiro.

É usual, especialmente fora da lógica, que a discussão sobre contradições gire em torno do $P N C$. Mas o maior problema para contextos argumentativos contraditórios, como vimos, é o princípio da explosão. Por essa razão, uma discussão sobre contradições não pode deixar de lado o princípio da explosão. Lógicas paraconsistentes são teorias da consequência lógica cuja característica distintiva é rejeitar o princípio da explosão. Assim, em um contexto argumentativo cuja lógica subjacente é paraconsistente, contradições podem ser aceitas sem trivialidade. O objetivo deste texto é apresentar um breve relato de como contradições e o princípio da explosão foram pensados no decorrer da história da filosofia, da formulação aristotélica do $P N C$ até a paraconsistência contemporânea, passando pela formulação do $E X P$ na Idade Média e pela discussão sobre contradições na modernidade, especialmente em Hegel.

\section{0 princípio da não contradição em Aristóteles}

Aristóteles, na Metafísica, apresenta três versões do $P N C$, quais sejam: ontológica, psicológica e linguística. Elas recebem essa classificação na literatura por falarem, respectivamente, do ser, de pensamentos, e de proposições. A versão ontológica é a seguinte:

[S] uch a principle is the most certain of all; which principle this is, we proceed to say. It is, that the same attribute cannot at the same time belong and not belong to the same subject in the same respect (ARISTÓTELES, 1991, Metaphysics 1005b15).

Essa versão pode ser refraseada da seguinte forma:

(PNC) Para qualquer objeto $a$ e propriedade $P, a$ não pode ter e não ter a propriedade $P$, simultaneamente e no que diz respeito ao mesmo aspecto.

A versão ontológica do PNC fala de objetos e propriedades. Essa distinção, que corresponde à distinção entre particulares e universais, 
é central em toda a história da filosofia e também nas ciências, e está presente na lógica de predicados clássica, onde o $P N C$ é representado pelo esquema de teorema

$$
\forall \mathrm{x} \sim(\mathrm{Px} \wedge \sim \mathrm{Px}),
$$

que significa: para todo $x$, não é o caso que $x$ satisfaz o predicado $P$ e $x$ não satisfaz o predicado $P$. As duas exigências da formulação de Aristóteles, ao mesmo tempo e sob o mesmo aspecto, estão implícitas na formulação acima, já que a lógica clássica não considera determinação temporal nem de perspectiva, logo não pode haver mais de uma única perspectiva nem diferentes determinações de tempo.

A versão psicológica diz:

[I]t is impossible for any one to believe the same thing to be and not to be, as some think Heraclitus says; for what a man says he does not necessarily believe. (ARISTÓTELES, 1991, Metaphysics 1005b25-30).

Essa versão é considerada falsa, por exemplo, por Łukasiewicz (1979) e Gottlieb (2015), pois é entendida como uma afirmação acerca de crenças em proposições: um mesmo agente não pode simultaneamente acreditar em $A$ e acreditar em $\sim A$. Mas isso é claramente falso, pois são vários os exemplos, inclusive na história da filosofia, em que contradições foram afirmadas como verdadeiras. Hegel e os dialeteístas contemporâneos seriam exemplos.

A versão linguística diz:

$[T]$ he most indisputable of all beliefs is that contradictory statements are not at the same time true (ARISTÓTELES, 1991, Metaphysics 1011b15).

Essa é uma afirmação acerca da verdade de proposições: não pode ser o caso que duas proposições $A$ e $\sim A$ sejam simultaneamente verdadeiras. Corresponde à tautologia da lógica proposicional clássica $\sim(A \wedge \sim A)$, que acaba sendo um caso especial da formulação mencionada acima da lógica de predicados. Mas há uma razão adicional para considerarmos que as 
versões ontológica e linguística colapsam: o dito de Aristóteles de que toda proposição é um dizer algo sobre algo. ${ }^{2}$ Essa tese, endossada pelas análises contemporâneas da forma lógica - por exemplo, as noções de função e argumento em Frege, e na noção de satisfação de Tarski - implica que a proposição $A$ mencionada na versão linguística seja analisada como uma predicação $P a$. Portanto, o princípio diz $\sim(P a \wedge \sim P a)$, um esquema que vale para todo objeto $a$ e toda propriedade $P$, expressando assim a mesma ideia da formulação da lógica de predicados.

Mas o que seria um contraexemplo para o $P N C$ ? O que tornaria o $P N C$ falso? Um objeto $a$ e uma propriedade $P$ tais que, simultaneamente e sob o mesmo aspecto, $P a$ e $\sim P a$ sejam ambas verdadeiras. Note, a título de exemplo, que a restrição "simultaneamente" impede que um indivíduo jovem, mas não jovem 50 anos depois, seja um contraexemplo, assim como a restrição "sob o mesmo aspecto" implica que uma circunstância em que duas pessoas mantidas em uma sauna e em um frigorífico sejam colocadas, respectivamente, em uma sala com temperatura $20^{\circ}$ Celsius, que estará fria para a primeira e quente (i.e. não fria) para a segunda, não viola o $P N C$.

\subsection{Heráclito}

Segundo uma leitura bastante comum de Heráclito, encontrada também em Aristóteles - por exemplo, no trecho citado acima da versão psicológica do $P N C$-, a doutrina heraclitiana da unidade dos opostos apresentaria violações ao $P N C$. Há razões, entretanto, para considerar essa leitura inadequada. Não é o meu objetivo aqui analisar em detalhe os fragmentos de Heráclito, mas apenas ilustrar a afirmação de que as teses de Heráclito podem ser interpretadas como diferentes perspectivas ou diferentes momentos do tempo. Considerem-se os fragmentos abaixo:

A água do mar é a mais pura e a mais poluída; para os peixes é saudável e salutar, mas para os homens é impotável e deletéria. (KIRK et al., fr. 61, p. 195)

\footnotetext{
2 "An affirmation is a positive assertion of something about something", Aristotle, On Interpretation $17 \mathrm{a} 25$.
} 
E como uma mesma coisa, existem em nós a vida e a morte, a vigília e o sono, a juventude e a velhice: pois estas coisas, quando mudam, são aquelas, e aquelas, quando mudam, são estas. (KIRK et al., fr. 88, p. 195)

Para os que entrarem nos mesmos rios, outras e outras são as águas que por eles correm ... Dispersam-se e ... reúnem-se ... juntas vêm e para longe fluem ... aproximam-se e afastam-se. (KIRK et al., fr. 12 e 91, p. 202)

Claramente, em todos os fragmentos acima, a suposta contradição pode ser eliminada se analisada em termos de diferentes perspectivas ou tempos diferentes. A água é pura e não pura segundo perspectivas diferentes; a vigília e o sono ocorrem em tempos diferentes; e o famoso fragmento do rio expressa a ideia, nada contraditória, da realidade como um fluxo constante.

\subsection{A silogística}

Embora Aristóteles rejeite enfaticamente contradições, o princípio de explosão não é válido na lógica aristotélica. Os escritos lógicos de Aristóteles estão reunidos no Organon, que não é propriamente um tratado de lógica, no sentido que usamos o termo hoje, mas sim um tratado de teoria da argumentação, que inclui a lógica, mas não se resume a ela. A silogística é uma lógica de conceitos, que são representados por predicados unários, e estuda o comportamento dedutivo dos quantificadores todo, algum e nenhum nas chamadas proposições categóricas, que são de quatro tipos:

Todo $X$ é $Y$ (afirmativa universal);

Algum $X$ é $Y$ (particular afirmativa);

Nenhum $X$ é $Y$ (negativa universal);

Algum $X$ é não $Y$ (particular negativa).

Esses tipos de proposições são chamados, respectivamente, de $A, I, E$ e $O$. Essa terminologia, posterior a Aristóteles, tem origem nas palavras latinas affirmo e nego, e foi estabelecida na Idade Média. 
Aristóteles estuda os argumentos que podem ser formulados com três proposições categóricas, duas premissas e uma conclusão, e lista as formas válidas. Algumas inferências podem ser feitas de premissas contraditórias quando o termo maior (o predicado da conclusão) é igual ao termo menor (o sujeito da conclusão). Nesse caso, todas as formas válidas com premissas $A$ e $O$, ou $E$ e $I$, produzem argumentos válidos com conclusão contraditória, por exemplo, a forma $A O O$ abaixo:

Todo Xé Y;

Algum Xé não $Y$;

Logo Algum Yé não Y.

Entretanto, não é o caso que se pode concluir qualquer proposição de premissas contraditórias, nem mesmo qualquer proposição categórica. Mesmo fazendo o termo maior igual ao termo menor, nenhum silogismo $A O A$ ou $E I A$ é válido. Mas se não é o caso que qualquer proposição se segue de uma contradição, o princípio da explosão não vale na lógica aristotélica. Mas isso não se deve, claro, a nenhuma espécie de tolerância a contradições.

\subsection{Lógica estoica}

A lógica estoica, diferentemente da lógica de Aristóteles, não é uma lógica de predicados, mas estuda o comportamento dedutivo dos conectivos não, e, ou (exclusivo), se... então. É, portanto, uma lógica proposicional. Esse tratamento em separado da lógica proposional e da lógica de predicados perdurou até fins do século XIX, quando Frege apresentou um sistema formal que unifica o tratamento dos conectivos proposicionais e quantificadores.

No entanto, o princípio de explosão não é explicitamente mencionado pelos estoicos. Um argumento que mais tarde, na Idade Média, vai "provar" o princípio da explosão (ver seção 3 abaixo) não pode ser elaborado na lógica estoica, porque esta trabalha com o ou exclusivo, e a referida prova depende essencialmente do ou inclusivo. Mas dependendo da leitura da condicional, EXP pode ser provado com base em inferências válidas na lógica estoica. São mencionadas quatro 
alternativas para interpretar a condicional, ${ }^{3}$ e de duas delas, a de Diodoro e a de Filo, o princípio de explosão, ou a inferência de que qualquer coisa se segue de uma proposição falsa, pode ser provado.

A condicional de Filo corresponde à condicional material da lógica clássica, e é também a condicional adotada por Frege na Conceitografia. É falsa apenas na circunstância em que o antecedente é verdadeiro e o consequente falso; em todas as outras é verdadeira, independentemente de uma relação entre os conteúdos do antecedente e do consequente. A prova de EXP dada a condicional de Filo é a seguinte:

$$
\begin{array}{ll}
\text { 1. } \mathrm{A} & \text { Premissa } \\
\text { 2. } \sim \mathrm{A} & \text { Premissa } \\
\text { 3. } \sim \mathrm{B} \rightarrow \mathrm{A} & \text { Condicional de Filo } \\
\text { 4. } \sim \mathrm{B} & \text { Segundo indemonstrável (modus tollens) } \\
\text { 5. } \mathrm{B} & \text { Dupla negação: } \sim \mathrm{B} \vdash \mathrm{B} .
\end{array}
$$

O passo 3 depende da condicional de Filo, pois sendo $A$ verdadeira, essa leitura da condicional permite concluir que qualquer proposição implica $A$, pois nunca teremos antecedente verdadeiro e consequente falso. $\mathrm{O}$ passo 4 resulta da aplicação do segundo indemonstrável dos estoicos às premissas 2 e 3 (ver KNEALE; KNEALE, 1962, p. 166), que corresponde ao princípio de inferência modus tollens. Essa prova depende também da dupla negação, a inferência que conclui B de B. Tanto Mates (1973, p. 31) quanto Bobzien (2016, seção 5.4) mencionam que os estoicos consideravam a dupla negação válida. Mas, além disso, a dupla negação pode ser obtida usando o terceiro excluído, aceito pelos estoicos, como premissa e o quinto indemonstrável (KNEALE; KNEALE, 1962, p. 172):

$$
\mathrm{A} \underline{\vee} \sim \mathrm{A}, \sim \sim \mathrm{A} \vdash \mathrm{A} .
$$

A inferência acima corresponde ao silogismo disjuntivo com ou exclusivo, representado pelo símbolo $\underline{\mathrm{V}}$.

${ }^{3}$ Sobre o debate estoico acerca da natureza da condicional, ver Kneale e Kneale (1962, pp. 130ss), e Mates (1973, pp. 48ss). 


\section{Ex Falso Quodlibet: o princípio da explosão na Idade Média}

O princípio da explosão tem esse nome porque faz "explodir" em trivialidade a teoria ou o contexto argumentativo em que a contradição ocorre. Mas esse princípio de inferência na Idade Média recebeu os nomes Ex Falso Quodlibet e Ex Contradictione Quodlibet. Pseudo-Escoto é o nome dado a um autor medieval desconhecido, nomeado dessa forma porque seus escritos foram erroneamente atribuídos a Duns Escoto. Em Pseudo-Escoto encontramos uma prova do princípio da explosão. Um aspecto importante dessa prova é que ela depende de leituras verofuncionais da disjunção e da conjunção que validem as inferências introdução da disjunção e eliminação da conjunção, válidas na lógica clássica. A prova usa também a regra de inferência denominada silogismo disjuntivo (com ou inclusivo), que das premissas $A \vee B$ e $\sim A$ permite concluir $B$ (KNEALE; KNEALE, 1962, p. 286-287).

$\begin{array}{ll}\text { 1. } A \wedge \sim A & \text { Premissa } \\ \text { 2. } A & \text { Eliminação da } \wedge \text {, linha } 1 \\ \text { 3. A } \vee \mathrm{B} & \text { Introdução da } \vee \text {, linha } 2 \\ \text { 4. } \sim \mathrm{A} & \text { Eliminação da } \wedge \text {, linha } 1 \\ \text { 5. } \mathrm{B} & \text { Silogismo disjuntivo, linhas } 3 \text { e } 4 .\end{array}$

Essa sequência de passos é uma prova muito comum do princípio da explosão. A ideia básica das regras utilizadas nessa prova é que preservação de verdade é condição suficiente para consequência lógica.

A concepção clássica de consequência lógica como preservação da verdade expressa a noção pré-teórica segundo a qual uma conclusão $B$ se segue de um conjunto de premissas $\Gamma$, se é impossível as premissas de $\Gamma$ serem verdadeiras e $B$ falsa. Essa noção foi estabelecida de modo preciso pelo lógico polonês Alfred Tarski nos anos de 1930: $B$ é consequência lógica de um conjunto de premissas $\Gamma$, se e somente se quaisquer que sejam os objetos acerca dos quais estivermos falando (i.e. o domínio de discurso), e qualquer que seja o modo de interpretar as expressões não lógicas da linguagem, não há uma circunstância (i.e., um domínio e uma interpretação) na qual todas as proposições de $\Gamma$ são verdadeiras, mas $B$ é 
falsa. O se e somente se da definição acima deixa claro que preservação da verdade é condição suficiente para consequência lógica, o que significa que basta ser impossível premissas verdadeiras e conclusão falsa para haver consequência lógica. Mas dado que não existe uma circunstância em que um par de proposições $A$ e $\sim A$ sejam simultaneamente verdadeiras (na leitura clássica da negação), será sempre impossível tornar $A \wedge \sim A$ verdadeira e $B$ falsa, para qualquer $B$. A validade de $E X P$, portanto, se segue da própria noção de consequência lógica como preservação de verdade.

Na Idade Média tardia (aproximadamente de 1300 a 1450) havia uma discussão intensa sobre como definir a noção de consequência lógica, embora sem consenso (ver KNEALE; KNEALE, 1962, p. 280ss). Mas dentro dessa discussão, havia uma concepção de consequência lógica similar à noção clássica atual, em termos de preservação de verdade. Em Kneale e Kneale (1962, p. 291) lemos que

Segundo a primeira explicação [de Pseudo-Escoto] é necessário e suficiente para a validade de uma consequentia que seja impossível para o antecedente ser verdadeiro e o consequente falso.

Embora não houvesse consenso, a ideia básica da definição moderna em termos de preservação de verdade já estava presente na discussão medieval sobre lógica. E é precisamente essa ideia, o critério "impossível premissas verdadeiras e conclusão falsa" não apenas como condição necessária mas também como condição suficiente, que justifica os passos da prova apresentada por Pseudo-Escoto do princípio da explosão.

\section{Contradições "hegelianas"}

A reflexão sobre a lógica no período final da Idade Média foi muito mais rica do que na modernidade. O princípio da explosão, que foi claramente formulado e "demonstrado" na Idade Média, não é objeto de discussão na modernidade. No período que vai aproximadamente do séc. XIV até o fim do século XIX, não houve desenvolvimentos significativos 
na lógica. É famosa a passagem em que Kant, na Crítica da Razão Pura, afirma que a lógica, desde Aristóteles, em nada progrediu, "parecendo, por conseguinte, acabada e perfeita, tanto quanto se nos pode afigurar" (KANT, 2001, BVIII). Sem dúvida, essa afirmação é equivocada. Não apenas porque uma transformação radical do estudo da consequência estava por vir, menos de dois séculos depois, iniciada por Frege e levada adiante por Russell, Gödel, Tarski, entre outros, mas também porque na Idade Média a lógica ultrapassou em muito o que foi feito na Antiguidade, por Aristóteles e pelos estoicos. Com efeito, a Lógica de Kant (1992) é muito mais um tratado sobre as faculdades do entendimento do que uma teoria da consequência lógica, e a Ciência da Lógica de Hegel (2010) não é uma teoria da consequência lógica, mas sim uma ontologia. Na verdade, a modernidade enfatizou de modo exagerado o aspecto psicológico da lógica, o que somente foi superado a partir do fim do século XIX, com o ataque de Frege ao psicologismo. Na chamada Lógica de Port Royal, uma obra de referência na modernidade, lemos que a lógica

is the art of conducting reasoning well in knowing things, as much to instruct ourselves about them as to instruct others. This art consists in reflections that have been made on the four principal operations of mind: conceiving, judging, reasoning, and ordering... [logic] serves three purposes. The first is to assure us that we are using reason well... The second is to reveal and explain more easily the errors or defects that can occur in mental operations. The third purpose is to make us better acquainted with the nature of the mind by reflecting on its actions. (ARNAULD; NICOLE, 1996, p. 23)

Além de estabelecer regras para o "uso correto da razão", Arnaud e Nicole estão interessados nas operações mentais relacionadas ao raciocínio em geral e na natureza da razão. O foco não é em uma análise da consequência lógica, embora este tema seja também tratado. O contexto em que a Arnaud e Nicole escrevem seu manual de lógica (1662) é o início da modernidade, pouco depois da publicação das obras de Descartes Discurso do Método (1637) e Meditações (1641). É 
precisamente nesse período que a reflexão sobre a subjetividade passa a ocupar um lugar central na filosofia. Kant, por exemplo, define a lógica como a "ciência das leis necessárias do entendimento e da razão em geral, ou - o que dá no mesmo - da mera forma do pensamento em geral" (KANT, 1992, p. 30), e na Crítica da Razão Pura (KANT, 2001) leva a cabo uma análise da estrutura da subjetividade que tinha como objetivos não apenas estabelecer limites para a metafísica mas também fundamentar a ciência que havia surgido há pouco, a física de Newton. E a concretização desses objetivos, para Kant, exige uma análise da razão humana enquanto ferramenta do conhecimento.

Mas se do ponto de vista técnico não houve um desenvolvimento significativo da lógica na modernidade, o mesmo não pode ser dito acerca da discussão conceitual da natureza das contradições, que deve ser compreendida no contexto da análise da subjetividade como um problema central da reflexão filosófica. Em Hegel essa discussão alcança seu ponto máximo.

A obra de Hegel deve ser compreendida como uma resposta a Kant. Para este, contradições não são toleradas, e a ocorrência de uma contradição é sinal inequívoco de erro. Para mostrar que a razão, quando ultrapassa seus limites, que são estabelecidos por aquilo que pode ser um objeto da experiência, pode cair em erro, Kant "prova" teses contraditórias, por exemplo, que o mundo tem um começo no tempo e limites no espaço e, por outro lado, que o mundo é infinito no tempo e não tem limites no espaço (KANT, 2001, B454). O princípio da não contradição, segundo ele, tem uma função puramente negativa: a conjunção de proposições contraditórias será sempre falsa. Sendo assim, contradições são um sinal inconfundível de erro, porque a realidade não é, de modo algum, contraditória. É importante chamar atenção para dois pontos na análise de Kant: (i) é a subjetividade que, ao errar, produz contradições; (ii) a separação radical entre sujeito e objeto, entre subjetividade e "mundo exterior", que resulta da sua análise das condições de possibilidade do conhecimento teórico e estabelece limites para o que pode ser conhecido. São esses os dois pontos que terão um papel central para entender a crítica de Hegel a Kant. 
Hegel não concorda com a separação radical entre sujeito e objeto estabelecida pela teoria do conhecimento de Kant. Para Hegel, o conhecimento deve ser absoluto. Hegel fala do absoluto tanto como substantivo quanto como um adjetivo. Embora essa noção à primeira vista possa parecer hermética, há uma metáfora muito útil para entendê-la: fora e dentro. Podemos começar com o significado corrente, pré-teórico, de absoluto. Se consultarmos um dicionário, certamente vamos encontrar que absoluto é aquilo que não tem restrição, é completo, incondicionado, perfeito. Em outras palavras, e levando essa caracterização ao pé da letra, nada pode estar fora do absoluto, pois se algo estiver fora, o absoluto não será mais perfeito, completo, irrestrito, logo não será mais absoluto. Daí se segue que o absoluto não pode ser "visto de fora", pois essa perspectiva exterior implica que o que está sendo visto não é mais absoluto. Raciocínios análogos podem ser aplicados ao adjetivo: a verdade absoluta deve ser toda a verdade, o conhecimento absoluto deve ser conhecimento da totalidade e não pode estar sujeito a nenhuma perspectiva em particular. Dessa caracterização do absoluto segue-se que: (i) o absoluto é incompatível com a separação entre sujeito e objeto, e (ii) o absoluto não pode estar separado ou fora do espaço-tempo; pelo contrário, o espaço-tempo deve também estar dentro do absoluto.

Hegel é conhecido como o filósofo que teria afirmado que há "contradições por toda a parte", e por conseguinte teria rejeitado o princípio da não contradição. De fato, à primeira vista, isso é o que se lê em Hegel:

"All things are in themselves contradictory" ... this proposition contrasted with the other [PNC] expresses rather the truth and the essence of things. (HEGEL, 2010, p. 381).

$[\mathrm{O}]$ rdinary experience itself testifies that there do exist at least a great many contradictory things ... of which the contradiction is present not in any external reflection but right in them. Nor is contradiction to be taken as an abnormality which happens only here and there, but it is rather ... the principle of all self-movement which consists in 
nothing else than in the display of contradiction. (HEGEL, 2010, p. 382).

A passagem acima citada parece estar em perfeita oposição com o princípio da não contradição. Mas cabe perguntar o que seriam um objeto $a$ e uma propriedade $P$ tais que $P a$ e $\sim P a$ são verdadeiras. Quais são os exemplos de contradições dados por Hegel? Há uma passagem famosa e bastante ilustrativa na Fenomenologia do Espírito:

The bud disappears in the bursting-forth of the blossom, and one might say that the former is refuted by the latter; similarly, when the fruit appears, the blossom is shown up in its turn as a false manifestation of the plant, and the fruit now emerges as the truth of it instead. These forms are not just distinguished from one another, they also supplant one another as mutually incompatible. Yet at the same time their fluid nature makes them moments of an organic unity in which they not only do not conflict, but in which each is as necessary as the other; and this mutual necessity alone constitutes the life of the whole. (HEGEL, 1977, §2, p. 2)

Mas claramente o desenvolvimento da planta, do botão até o fruto, não é um contraexemplo para o $P N C$, pois os predicados $x$ é um botão e $x$ não é um botão etc., não se aplicam simultaneamente. Mas por que Hegel enfatiza tanto esse "aspecto contraditório da realidade"? Em que Hegel está de fato interessado? O seguinte trecho, junto com as observações feitas acima sobre o absoluto, esclarece esse ponto.

The True is the whole. But the whole is nothing other than the essence consummating itself through its development. Of the Absolute it must be said that it is essentially a result, that only in the end is it what it truly is; and that precisely in this consists its nature, viz. to be actual, subject, the spontaneous becoming of itself. (HEGEL, 1977, §20, p. 11)

O absoluto, que vimos acima como substantivo, pode de modo análogo ser aplicado como adjetivo. A verdade absoluta é o todo, e o todo é a "totalidade do processo". Parece-me absolutamente correto afirmar que 
a verdade não está no botão, nem na flor, nem no fruto, mas sim em todo o processo de desenvolvimento da planta, e será alcançada somente ao fim do processo. Considerado como uma totalidade, esse processo contém contradições apenas em um "sentido fraco", pois um mesmo objeto instancia propriedades contraditórias em diferentes momentos. Não é difícil perceber, diga-se de passagem, que tais "contradições" são similares às oposições de Heráclito.

Essa noção de verdade como totalidade pode ser estendida para a totalidade do real. O conhecimento absoluto, que pela reflexão de Kant é impossível, para Hegel somente pode ser alcançado pela superação da separação entre sujeito e objeto. E isso é uma consequência da noção de absoluto, pois se o conhecimento do real for de um sujeito separado daquilo que é conhecido, o conhecimento deixará sempre algo "do lado de fora" e, portanto, não será absoluto. Não é difícil perceber que a única alternativa para superar a separação sujeito/objeto e alcançar o conhecimento absoluto é a realidade conhecer a si mesma. E é precisamente esse o resultado final de todo o processo: uma espécie de "autoconsciência universal" em que a totalidade do real é capaz de pensar sobre si mesma, articulando de modo racional em uma unidade todos os momentos e todos os aspectos de seu desenvolvimento. Mas é nesse todo articulado que ocorrem as contradições. O pensamento, ao agrupar em uma unidade todos os momentos que constituem o movimento do real - movimento similar ao concebido por Heráclito - reúne vários momentos e perspectivas diferentes em que propriedades contraditórias instanciaram um mesmo objeto.

A obra de Hegel é imensa, e não se pode concluir do exposto acima que todas as contradições que Hegel menciona não são de fato violações do $P N C$. Mas eu deixo aqui como uma conjectura, a ser eventualmente trabalhada por especialistas, que não existem contradições em Hegel no sentido de violações ao PNC tal como formulado por Aristóteles e expressado pela lógica de predicados clássica. Mas isso não tira a importância do pensamento de Hegel, que é fundamental para compreender diversos fenômenos da história, da natureza e da própria subjetividade. Além disso, contradições fazem parte da heurística da 
criação/descoberta científica, algo reconhecido mesmo por matemáticos (BYERS, 2007). O fato de a versão psicológica do PNC ser falsa, como vimos na seção 2, aponta para uma característica importante da mente humana, pois é a mente que reúne em uma unidade dados ou informações contraditórias nos mais variados contextos argumentativos. Mas o ponto que eu gostaria de enfatizar aqui é que as "contradições hegelianas" têm caráter epistêmico no sentido que ocorrem no pensamento, e tais contradições têm um parentesco com as chamadas contradições epistêmicas, que ocupam um papel central no desenvolvimento da lógica paraconsistente. Vimos acima que, para Kant, as contradições ocorrem apenas na subjetividade e são indicação de erro, pois não podem ocorrer no mundo, na "realidade exterior". Hegel discorda de Kant, conforme se pode observar:

[According to Kant] The stain of contradiction ought not to be in the essence of what is in the world; it has to belong only to thinking reason, to the essence of the spirit [mind]. It is not considered at all objectionable that the world as it appears shows contradictions to the spirit [mind] that observes it; the way the world is for subjective spirit, for sensibility, and for the understanding, is the world as it appears ... [The true significance of the Kantian antinomies is that] Everything actual contains opposed determinations within it, and in consequence the cognition and, more exactly, the comprehension of an object amounts precisely to our becoming conscious of it as a concrete unity of opposed determinations. (HEGEL, 1991, p. 92, §48)

Hegel menciona a visão kantiana, rejeitada por ele, de que contradições têm lugar apenas na mente, no pensamento. E a afirmação de que compreender um objeto significa apreendê-lo como uma unidade de propriedades contraditórias é explicada pelo exemplo acima, do desenvolvimento da planta, do botão à flor, e Hegel está certo nesse ponto, independentemente de tais situações não violarem o $P N C$. A afirmação de que contradições "pertencem às coisas mesmas" se segue da reunião de sujeito e objeto em uma unidade. Dado que o absoluto, o 
conhecimento absoluto, a verdade absoluta não podem deixar nada "de fora", o estágio final do processo, que seria, por assim dizer, o próprio absoluto, colapsa os aspectos ontológico e epistemológico.

De fato, a única maneira de superar a separação kantiana entre sujeito e objeto é reunir em uma unidade toda a realidade, natureza, história e subjetividade, e tal unidade ser autoconsciente de si mesma, pensar a si mesma, conhecer a si mesma. A meu ver, essas ideias de Hegel devem ser entendidas hoje como uma alegoria, sem entrar em discussões sobre a plausibilidade de uma "consciência universal". Hegel fornece ferramentas teóricas muito úteis, e é isso o que deve ser enfatizado.

\section{Paraconsistência e contradições epistêmicas}

A tese de que contradições têm lugar apenas no pensamento se opõe ao dialeteísmo contemporâneo, defendido por Graham Priest e seus colaboradores. O dialeteísmo afirma que existem contradições verdadeiras, pares de proposições $A$ e $\sim A$, tais que ambas são verdadeiras, e tais proposições são denominadas dialetéias (PRIEST; BERTO, 2017).

$\mathrm{O}$ dialeteísmo é uma visão ontológica das contradições. Para descrever a realidade corretamente, precisamos de pares de proposições contraditórias, porque aquilo que está sendo descrito, a realidade propriamente dita, possui contradições. E é claro que um dialeteísta terá de rejeitar o princípio de explosão, pois a realidade obviamente não é trivial. Ser dialeteísta, portanto, implica adotar uma lógica paraconsistente. Por outro lado, paraconsistência não implica dialeteísmo, pois há inúmeros contextos argumentativos reais que são contraditórios mas que lidam com contradições epistêmicas. Contradições epistêmicas têm origem em limitações do nosso aparato cognitivo, na heurística da investigação científica, na inabilidade das atuais teorias de lidar com os dados disponíveis, em imperfeições dos instrumentos de medida usados nos experimentos, ou até mesmo em simples erros que podem, ou não, ser posteriormente corrigidos.

A lógica clássica não é o único tratamento disponível da noção de consequência lógica. Há diversas alternativas diferentes, as chamadas lógicas não clássicas. Dentre as lógicas não clássicas, vou mencionar 
duas: a lógica intuicionista, que é uma formalização das ideias do matemático holandês L. E. Brouwer (ver RODRIGUES, 2011, p. 70ss), e a lógica paraconsistente, cuja ideia básica pode ser encontrada no início do século XX nas reflexões do lógico russo Nicolai Vasiliev, mas que foi definitivamente estabelecida como área de estudo em lógica e filosofia da lógica nos anos de 1960 pelo lógico brasileiro Newton da Costa. ${ }^{4}$ A lógica intuicionista invalida o terceiro excluído, o que significa que admite circunstâncias em que simultaneamente $A$ não é o caso, e $\sim A$ não é o caso. A lógica paraconsistente é como uma imagem no espelho da lógica intuicionista, pois admite circunstâncias em que simultaneamente $A$ é o caso, e $\sim A$ é o caso, rejeitando dessa forma o princípio de explosão.

Mas cabe perguntar se nas lógicas intuicionista e paraconsistente trata-se de afirmar que ambas as proposições $A \mathrm{e} \sim A$ são, respectivamente, falsas e verdadeiras. Vou me concentrar aqui apenas no caso da paraconsistência, mas uma abordagem mais detalhada desse problema pode ser encontrada em Carnielli e Rodrigues (2015 e 2017). Como alternativa, diga-se de passagem muito mais plausível, ao dialeteísmo, podemos considerar que a propriedade atribuída a um par de proposições contraditórias tem caráter epistêmico e é uma propriedade mais fraca que verdade, no sentido que uma proposição pode possuir tal propriedade mas não ser verdadeira. A contradição, dessa forma, ocorre apenas na perspectiva sintática, como uma proposição da forma $A \wedge \sim A$, ou um par de proposições $A$ e $\sim A$. Essa propriedade mais fraca que verdade pode ser a noção de evidência, no sentido de razões para acreditar em ou aceitar uma dada proposição (ver CARNIELLI e RODRIGUES, 2017, seções 1 e 2). Há situações, por exemplo, em que recebemos informações conflitantes mas não podemos descartá-las, pois em princípio há boas razões para acreditar em ambas. Tais contextos argumentativos lidam com uma propriedade de proposições mais fraca que a noção de verdade, que denominamos evidência não conclusiva. Nessa perspectiva, a lógica paraconsistente não precisa se comprometer com a tese controversa defendida pelo dialeteísmo, e além disso pode conviver em harmonia com a lógica clássica, pois cada um desses tratamentos da consequência lógica

\footnotetext{
${ }^{4}$ Para uma abordagem histórica da paraconsistência, ver Gomes (2013).
} 
trata de assuntos diferentes: a lógica paraconsistente, assim interpretada, trata de preservação de disponibilidade de evidência, enquanto a lógica clássica trata de preservação da verdade.

O que eu tentei apresentar aqui foi uma breve história da contradição e do princípio da explosão, tendo como fio condutor os períodos em que a história da filosofia é dividida. Há muita literatura sobre o assunto, tanto do ponto de vista conceitual quanto técnico. Contradições nas ciências empíricas não são incomuns, e são tratadas muito mais como características das teorias, ou resultados dos dados disponíveis, do que tendo origem na realidade (NICKLES 2002). A computação lida rotineiramente com bancos de dados inconsistentes, e nem por isso nossos computadores param de funcionar - sim, eles travam, mas não necessariamente por essa razão. O fato é que contradições foram, desde os gregos, um tema central da filosofia, embora a caracterização precisa do que é uma contradição não seja sempre a mesma. E essa discussão permanece viva.

\section{Referências}

ARISTÓTELES. The Complete Works of Aristotle. Ed. Jonathan Barnes. Princeton: Princeton University Press, 1991.

ARNAULD, A.; NICOLE, P. Logic or the Art of Thinking. Ed. J. V. Buroker. Cambridge: Cambridge University Press, 1996.

BOBZIEN, S. Ancient Logic. In: ZALTA, E. N. (Ed.). The Stanford Encyclopedia of Philosophy. Stanford: Stanford University, 2016. Disponível em: <https://plato.stanford.edu/archives/win2016/entries/ logic-ancient/>.

BYERS, W. How Mathematicians Think. Princeton: Princeton University Press, 2007.

CARNIELLI, W.; RODRIGUES, A. Paraconsistency and Duality: between Ontological and Epistemological Views. In: ARAZIM, Pavel; DANCAK, Michal (Ed.). The Logica Yearbook 2015. New York: College Publications, 2016. 
CARNIELLI, W.; RODRIGUES, A. An epistemic approach to paraconsistency: a logic of evidence and truth. Synthese, [s.1.], Nov. 2017. Preprint disponível em: < https://goo.gl/ncfSZw>. DOI: https://doi. org/10.1007/s11229-017-1621-7

GOTTLIEB, P. Aristotle on Non-contradiction. In: ZALTA, E. N. (Ed.). The Stanford Encyclopedia of Philosophy. Stanford: Stanford University, 2016. Disponível em https:// plato.stanford.edu/archives/sum2015/ entries/aristotle-noncontradiction/.

GOMES, E. L. Sobre a História da paraconsistência e a obra de da Costa: a instauração da lógica paraconsistente. 2013. 704 f. Tese (Doutorado) - Universidade Estadual de Campinas, Campinas, 2013

KANT, I. Crítica da Razão Pura. Trad. M. P. dos Santos e A. F. Morujão. Lisboa: Calouste Gulbenkian, 2001.

KANT, I. Lógica. Trad. G.A. de Almeida. Rio de Janeiro: Tempo Brasileiro, 1992.

KIRK, G. S.; RAVEN, J. E.; SCHOFIELD, M. Os filósofos présocráticos. Lisboa: Calouste Gulbenkian, 1994.

HEGEL, G. W. F. The Science of Logic. Trad. George di Giovanni. Cambridge: Cambridge University Press, 2010.

HEGEL, G. W. F. Phenomenology of Spirit. Trad. A. V. Miller. Oxford: Oxford University Press, 1977.

HEGEL, G. W. F. The Encyclopedia Logic. Trad. T. F. Geraets, W. A. Suchting e H. S. Harris. Indianapolis: Hackett Publishing, 1991.

KNEALE, W.; KNEALE, M. O desenvolvimento da lógica. Lisboa: Calouste Gulbenkian, 1962.

ŁUKASIEWICZ, J. Aristotle on the Law of Contradiction. In: BARNES, J.; SCHOFIELD, M.; SORABJI, R. (Ed.). Articles on Aristotle: Metaphysics. London: Duckworth, 1910. [1979].

MATES, B. Stoic Logic. Berkeley: University of California Press, 1973.

NICKLES, T. From Copernicus to Ptolemy: inconsistency and method. In: MEHEUS, J. (Ed.). Inconsistency in Science. Dordrecht: Springer, 2002. 
PRIEST, G. Aristotle on the Law of Non-Contradiction. In: Doubt Truth to be a Liar. Oxford: Oxford University Press, 2005. PRIEST, G.; BERTO, F. Dialetheism. In: ZALTA, E. N. (Ed.). The Stanford Encyclopedia of Philosophy. Stanford: Stanford University, 2017. Disponível em https: <//plato.stanford.edu/archives/spr2017/ entries/dialetheism/.>

RODRIGUES, A. Lógica. São Paulo: Martins Fontes, 2011.

Recebido em 10 de outubro de 2017. Aprovado em 15 de novembro de 2017. 